\title{
Effect of Combination of Acapella Device and Breathing Exercises on Treatment of Pulmonary Complications After Upper Abdominal Surgeries
}

\author{
Nesma M. Allam ${ }^{1}$, Mohammed M. Khalaf ${ }^{1}$, Wael N. Thabet ${ }^{2}$, Zizi M. Ibrahim ${ }^{1}$ \\ ${ }^{1}$ Department of Physical Therapy for Surgery, Faculty of Physical Therapy, Cairo University, Cairo, Egypt \\ ${ }^{2}$ Department of General Surgery, Faculty of Medicine, Cairo University, Cairo, Egypt
}

\section{Email address:}

Dr.nesma2011@yahoo.com (N. M. Allam)

\section{To cite this article:}

Nesma M. Allam, Mohammed M. Khalaf, Wael N. Thabet, Zizi M. Ibrahim. Effect of Combination of Acapella Device and Breathing Exercises on Treatment of Pulmonary Complications After Upper Abdominal Surgeries. Journal of Surgery. Special Issue: Gastrointestinal Surgery: Recent Trends. Vol. 4, No. 2-1, 2016, pp. 10-14. doi: 10.11648/j.js.s.2016040201.13

\begin{abstract}
Introduction: Background. Upper abdominal surgery alters postoperative pulmonary function, as observed by impairment of lung volumes such as total lung capacity, vital capacity. Impaired clearance of sputum results in a vicious cycle of colonization and infection of bronchi with pathogenic organisms, dilation of bronchi and further production of sputum. The aim was to investigate the effect of combination of Acapella device and breathing exercises on treatment of post operative pulmonary complications after upper abdominal surgeries. Subjects and methods: Sixty patients underwent upper abdominal surgery were assigned randomly into two equal groups; their ages ranged from 20-50 years. The study group received breathing exercises, Acapella device and traditional chest physical therapy program (postural drainage. percussion, vibration, cough training and early ambulation). Control group received traditional chest physical therapy program (postural drainage. percussion, vibration, cough training and early ambulation). All groups received three sessions per week for four successful weeks. The data were collected before and after the same period of treatment for both groups. Evaluation procedures were carried out to measure pulmonary function: Forced vital capacity (FVC) and Forced expiratory volume in one second (FEV1) using electronic spirometer. Results: Post treatment results showed that there was a significant improvement difference in FVC and FEV1 in both groups in favor of the study group. Percentage of improvement of FVC in the study group was $42.28 \%$, while it was $16.31 \%$ in the control group. Percentage of improvement of FEV1 in the study group was $49.05 \%$, while it was 20.79\% in the control group. Conclusion: Combination of Acapella device and breathing exercises were considered to be an effective modality for treatment of postoperative pulmonary complications and removal of secretions after upper abdominal surgeries.
\end{abstract}

Keywords: Acapella Device, Breathing Exercises, Pulmonary Complications, Spirometer, Upper Abdominal Surgeries

\section{Introduction}

Patients submitted to upper abdominal surgery (UAS) usually develop a restrictive lung pattern, with changes to pulmonary mechanics in the first post operative days. This can cause a reduction in inspiratory capacity, total inspiratory time, and ventilation at the lung bases, leading to a high risk of developing post operative pulmonary complications (PPCs) [1]. For adequate pulmonary ventilation to occur, it is fundamental that the forces that act on the respiratory system favor the thoracic and abdominal movements, especially the respiratory muscle strength that is compromised after UAS [2].
A major decline in pulmonary function [Forced vital capacity (FVC) and Forced expiratory volume in one second (FEV1)] is observed on the first day after upper abdominal surgery. This decline can reduce vital and inspiratory capacity and can culminate in restrictive lung diseases that cause atelectasis, reduced diaphragm movement, and respiratory insufficiency [3].

PPC defined as new onset or exacerbation of respiratory failure following surgery, occur frequently [4]. A thorough understanding of the clinical effects of PPC is hindered by inconsistency in the definition of PPC among researchers. The diagnoses classically considered PPC including atelectasis, bronchospasm, pneumonia, pulmonary edema, 
and respiratory failure. Respiratory failure itself is not clearly defined, although the most common criterion is failure to be extubated within 48 hours of surgery [5].

Airway secretions, particularly those in peripheral airways, require a forced expiratory maneuver for expectoration. To facilitate passage of air to alveoli beyond the secretions, a deep breathing maneuver is adopted prior to the application of forced expiratory techniques [6].

The Acapella (Smiths Medical Inc, Carlsbad, California, USA) is a handheld airway clearance device that operates on the same principle as the Flutter, i.e. a valve interrupting expiratory flow generating oscillating PEP. Utilizing a counterweighted plug and magnet to achieve valve closure, the Acapella is not gravity dependent like the Flutter. The Acapella comes in three models, a low flow $(<15 \mathrm{~L} / \mathrm{min})$, high flow $(>15 \mathrm{~L} / \mathrm{min})$ and the Acapella Choice. The high and low flow models have a dial to set expiratory resistance while the Choice model has a numeric dial to adjust frequency [7].

Oscillating devices such as the flutter and acapella have a twofold effect on secretion clearance. Oscillation has been shown to decrease the viscoelastic properties of mucus hence making it easier to mobilize up the airways. The second effect of the oscillations is to cause short bursts of increased acceleration of the expiratory airflow which assist in mobilizing the secretions up the airways [8].

The aim of this study was to investigate the effect of combination of Acapella device and breathing exercises in treatment of post operative pulmonary complications after upper abdominal surgeries.

\section{Subjects, Materials and Methods}

This study was carried out on 60 adult patients of both sexes suffering from pulmonary complications and accumulation of secretions after upper abdominal surgery, their ages ranged from 20 to 50 years and selected from general surgery department at Om El Masryeen Hospital, Giza, Egypt during the period of February2015 to August 2015.Patients were randomly assigned into two equal groups; Group A (Study group) and Group B (Control group).Group A received deep breathing exercises, Acapella device and traditional chest physical therapy program (postural drainage. percussion, vibration, cough training and early ambulation)and group B received traditional chest physical therapy program (Postural drainage, percussion, vibration, cough training and early ambulation).

Patients with the following conditions were excluded from the study; malignant disease, infection, active inflammation or sepsis. Patients spent more than 48 hours on mechanical ventilation, Instability of patient's medical condition, heavy smokers, alcohol drinking and patient with any spirometry contra-indications (e.g. Unstable cardiovascular status, pneumothorax, active hemoptysis and abdominal or cerebral aneurysms) were also excluded.

The work has been carried out in accordance with the ethics of committee for experiments at Faculty of Physical
Therapy, Cairo University involving humans, and parents filled approval consent to share in the study.

The assessment approach was: Spirometer which is a computerized instrument that records: forced vital capacity (FVC) and forced expiratory volume in the first second (FEV1) at the beginning of the study (1st day post operative) and after four successive weeks.

Preparation of Acapella device: The Acapella adjustment frequency dial turned counterclockwise to lowest resistance setting. As the patient improve, adjust proper resistance upward by turn the dial clockwise, the patient instructed to: 1- Sit in a comfortable position. 2- Take in breath that larger than normal but not to fill the lunges completely.3- Position the mouthpiece maintaining a tight seal with his lips. 4- Hold breath for 2 or $3 \mathrm{sec}$. 5- Try not to cough and exhale slowly for 2 to $3 \mathrm{sec}$ through the device while it vibrates. 6- Remove the mouthpiece and cough or "huff cough". To huff cough, take a deep breath. Hold it for 1-3 seconds. Then, force air out of his lungs with his mouth open like he would do if he were trying to fog a mirror. 7- Continue breathing with the Acapella with breaks to cough about every 5 minutes for a total treatment time of $20-30$ minutes [9].

Statistical Analysis

Descriptive statistics and T- test for comparison of the mean age of both groups. Independent T-test for comparison of FVC and FEV1 between both groups. Paired T-test for comparison between pre and post treatment mean values of FVC and FEV1 in each group. The level of significance for all statistical tests was set at $p<0.05$. All statistical tests were performed through the statistical package for social studies. (SPSS) version 19 for windows (IBM SPSS, Chicago, IL, USA).

\section{Results}

The statistical analysis for patient's socio-demographic data (age, sex) revealed a non significant difference between both groups.

Results revealed that; There was no significant difference in mean values of FVC between both groups pre treatment ( $p$ $=0.26$ ). While there was a significant increase in FVC in group A post treatment compared to that of group B ( $p=$ 0.0001 ) as shown in tableland figure1.

There was no significant difference in mean values of FEV1 between both groups pre treatment $(p=0.41)$. While there was a significant increase in FEV1 in group A post treatment compared to that of group B $(p=0.0001)$ as shown in table 2 and figure 2.

Table 1. Pre and post treatment results of FVC for both groups.

\begin{tabular}{lllll}
\hline & \multicolumn{2}{l}{ Pre treatment } & \multicolumn{2}{l}{ Post-treatment } \\
\cline { 2 - 5 } & Group A & Group B & Group A & Group B \\
\hline $\mathrm{X}$ & 1.49 & 1.41 & 2.12 & 1.64 \\
$\mathrm{SD} \pm$ & \pm 0.23 & \pm 0.26 & \pm 0.33 & \pm 0.32 \\
$\mathrm{t}-$ value & 1.13 & & 5.61 & \\
p- value & 0.26 & & 0.0001 & \\
Significance & Non significant & Significant \\
\hline
\end{tabular}


Table 2. Pre and post treatment results of FEV1 for both groups.

\begin{tabular}{lllll}
\hline & Pre treatment & \multicolumn{3}{c}{ Post-treatment } \\
\cline { 2 - 5 } & Group A & Group B & Group A & Group B \\
\hline $\mathrm{X}$ & 1.06 & 1.01 & 1.58 & 1.22 \\
$\mathrm{SD} \pm$ & \pm 0.16 & \pm 0.22 & \pm 0.24 & \pm 0.24 \\
$\mathrm{t}-$ value & 0.83 & & 5.55 & \\
$\mathrm{p}-$ value & 0.41 & & 0.0001 & \\
Significance & Non significant & \multicolumn{3}{c}{ Significant } \\
\hline
\end{tabular}

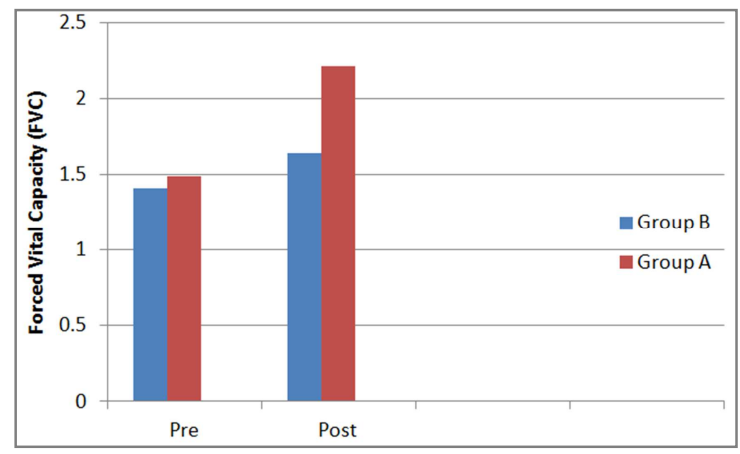

Figure 1. Pre and Post-treatment mean values of FVC (L) for both groups.

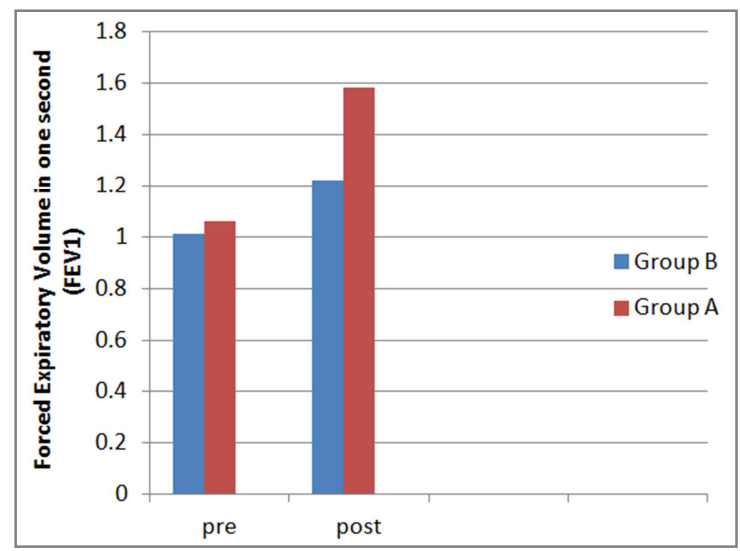

Figure 2. Pre and Post-treatment mean values of FEV1 (L) for both groups.

Statistical analysis of results showed a significant improvement in FVC and FEV1 in group A and group B after 4 weeks of treatment as follows:

Results of FVC: The mean \pm SD pre treatment of group A was $1.49 \pm 0.23 \mathrm{~L}$ and that post treatment was $2.12 \pm 0.33 \mathrm{~L}$. The mean difference was $-0.63 \mathrm{~L}$ and the percent of improvement was $42.28 \%$. There was a significant increase in mean value of FVC post treatment compared with pre treatment in group A $(p=0.0001)$. While in group B the mean \pm SD of FVC pre treatment was $1.41 \pm 0.26 \mathrm{~L}$ and that post treatment was $1.64 \pm 0.32 \mathrm{~L}$. The mean difference was $0.23 \mathrm{~L}$ and the percent of improvement was $16.31 \%$. There was a significant increase in mean value of FVC post treatment compared with pre treatment in group $\mathrm{B}(\mathrm{p}=$ 0.0001 ) as shown in table 3 and figure 3.

Results of FEV1: The mean \pm SD pre treatment of group A was $1.06 \pm 0.16 \mathrm{~L}$ and that post treatment was $1.58 \pm 0.24 \mathrm{~L}$. The mean difference was $-0.52 \mathrm{~L}$ and the percent of improvement was $49.05 \%$. There was a significant increase in mean value of FEV1 post treatment compared with pre treatment in group A $(p=0.0001)$. While in group B the mean $\pm \mathrm{SD}$ of FEV1 pre treatment was $1.01 \pm 0.22 \mathrm{~L}$ and that post treatment was $1.22 \pm 0.24 \mathrm{~L}$. The mean difference was $0.21 \mathrm{~L}$ and the percent of improvement was $20.79 \%$. There was a significant increase in mean value of FEV1 post treatment compared with pre treatment in group $\mathrm{B}(\mathrm{p}=$ 0.0001 ) as shown in table 4 and figure 4.

Table 3. Pre and post treatment results of FVC for each group.

\begin{tabular}{lllll}
\hline & Group A & \multicolumn{3}{l}{ Group B } \\
\cline { 2 - 5 } & Pre & Post & Pre & Post \\
\hline $\mathrm{X}$ & 1.49 & 2.12 & 1.41 & 1.64 \\
$\mathrm{SD} \pm$ & \pm 0.23 & \pm 0.33 & \pm 0.26 & \pm 0.32 \\
t- value & -11.37 & & -6.69 & \\
p- value & 0.0001 & & 0.0001 & \\
Significance & Significant & \multicolumn{3}{|c}{ Significant } \\
\hline
\end{tabular}

Table 4. Pre and post treatment results of FEV1 for each group.

\begin{tabular}{lllll}
\hline & Group A & \multicolumn{3}{l}{ Group B } \\
\cline { 2 - 5 } & Pre & Post & Pre & Post \\
\hline $\mathrm{X}$ & 1.06 & 1.58 & 1.01 & 1.22 \\
$\mathrm{SD} \pm$ & \pm 0.16 & \pm 0.24 & \pm 0.22 & \pm 0.24 \\
$\mathrm{t}-$ value & -13.96 & & -9.88 & \\
p- value & 0.0001 & & 0.0001 & \\
Significance & Significant & & Significant \\
\hline
\end{tabular}

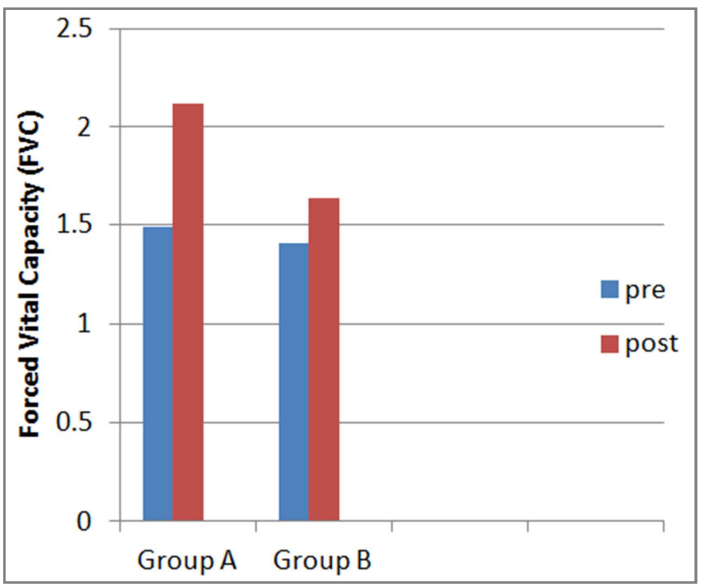

Figure 3. Mean values of pre and post treatment of $F V C$ (L) for each group.

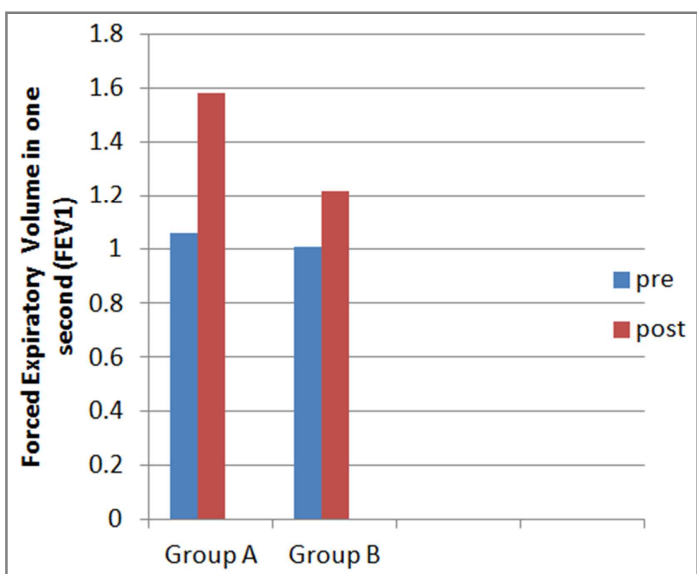

Figure 4. Mean values of pre and post treatment of FEV1 (L) for each group. 


\section{Discussion}

The findings of this study indicated that patients suffering from pulmonary complications following upper abdominal surgery had a significant improvement in FVC and FEV1 after application of Acapella device with breathing exercises. The statistical analysis revealed a significant improvement of FVC in the study group than that of the control group; the percentage of improvement was $42.28 \%$ and $16.31 \%$ for the two groups respectively. Also there is a significant improvement of FEV1 in the study group than that of the control group; the percentage of improvement was $49.05 \%$ and $20.79 \%$ for the two groups respectively.

These results are consistent with authors who supported that combination of Acapella device and breathing exercises is an effective modality in improving pulmonary function and reducing sputum after upper abdominal surgery as follows: after the use of oscillatory positive expiratory pressure (OPEP) there was a statistically significant $(\mathrm{p}<0.05)$ improvement in FEV1 23\% and FVC 43\% compared to baseline with combined bronchodilator therapy. As the OPEP devices have shown a significant increase in lung function parameters (FVC, FEV1 and forced expiratory flow) after more prolonged use in an outpatient setting [10].

The Acapella device characterization showed an oscillation frequency varying from $8 \mathrm{~Hz}$ to $21 \mathrm{~Hz}$, mean pressure ranging from $3 \mathrm{~cm} \mathrm{H} 2 \mathrm{O}$ to $23 \mathrm{~cm} \mathrm{H} 2 \mathrm{O}$, and oscillation amplitude from $4 \mathrm{~cm} \mathrm{H} 2 \mathrm{O}$ to $9 \mathrm{~cm} \mathrm{H} 2 \mathrm{O}$. These parameters increased with flow and instrument adjustment [11]. The Acapella devices elicit higher vibration amplitudes ( 5 to $8 \mathrm{cmH}_{2} \mathrm{O}$ ) than the water bottle $\left(1.8 \mathrm{cmH}_{2} \mathrm{O}\right)$. The Acapella devices may be more efficient for secretion mobilization than the water bottle, because they elicit greater amplitude of vibrations [12].

The OPEP provides an improvement both in pulmonary function tests (FVC, FEV1) and quality of life. This treatment should be included among the principal options in chest physiotherapy [13]. There was a significant improvement of FVC and FEV1 also arterial oxygen pressure $(\mathrm{PaO} 2)$, carbon dioxide pressure $(\mathrm{PaCO} 2)$ improved after 4 weeks in patients with chronic obstructive pulmonary diseases (COPD) after upper abdominal surgery [14].

Breathing exercises with positive expiratory pressure (PEP) are commonly recommended for the prevention of pulmonary complications after abdominal surgery. Scientific documentation of the effects of PEP treatment is limited. In total, $24(54 \%)$ of the physical therapists answered the questionnaire. All reported using breathing exercises with PEP as a treatment option after abdominal surgery [15].

Application of Acapella device for chest physiotherapy when compared with multimodality chest physiotherapy resulted in significant increase in the mean values of sputum amount, significant decrease in sputum viscosity, improved radiological signs of atelactasis, shorter duration of ventilator support, and less ICU stay. So, Acapella device is a good representative to all conventional multi-modality chest physiotherapy procedures with high success rate and can replace the exhausting, costy, and time consuming conventional procedures in COPD patients [16].

Positive expiratory pressure technique provides a significantly greater improvement in the pulmonary function when compared to postural drainage with percussion. Other procedures are also utilized such as the Flutter device, autogenic drainage, the positive expiratory pressure technique, forced expiration techniques and intrapulmonary percussive ventilation [17].

Pulmonary function tests: forced vital capacity (FVC), forced expiratory volume in the first second (FEV1), FEV1/FVC ratio, peak expiratory flow (PEF) and diaphragm excursion values between preoperative and postoperative (first, second) days were found to be higher in the exercise group diaphragmatic breathing exercise, (other therapies like bronchial hygiene therapy, Thoracic mobility exercise and mobilization)when compared to control group performed on twenty sample sizes who underwent laparoscopic surgery [18].In addition, the effect of breathing exercises during the immediate postoperative period following upper abdominal surgery seem to provide some benefit in improving pulmonary function, reducing pulmonary complications and postoperative hospital stay, as the study group showed significant improvement in FEV1 (21.47\%) $(\mathrm{P}<0.001)$, FVC $(12.96 \%)(\mathrm{P}<0.05)$ as compared to the control group [19].

In contrast it was found that there were no statistically significant differences among the airway clearance regimens of the active cycle of breathing techniques (ACBT), autogenic drainage (AD), positive expiratory pressure (PEP) and the oscillating PEP devices of the Flutter and RC when used over a period of one year, in the sitting position, by adults with cystic fibrosis. It is likely that to optimize adherence to treatment and consequently improvements in morbidity and mortality, the patient should be involved in the selection of his/her airway clearance regimen [20].

It was found that there was no significant difference between weight of sputum expectorated with ACBT treatment and weight of sputum expectorated with Acapella treatment .The Acapella is as effective method of airway clearance as ACBT and may offer a user-friendly alternative to ACBT for patients with bronchiectasis [21, 22].

From the gained results it could be concluded that combination of breathing exercises and Acapella device had a significant improvement of FVC and FEV1 and decrease of post operative pulmonary complications after upper abdominal surgery.

\section{References}

[1] Chiavegato L, Jardim J, Faresin S and Juliano Y. Altered respiratory function in laparoscopic cholecystectomy. J Pneumol; 2000, 26(2): 69-76.

[2] Grams S, Ono L, Noronha M, Schivinski C and Paulin E. Breathing exercises in upper abdominal surgery: A systematic review and meta- analysis. Revista Brasileira de Fisioterapia; 2012, 16 (5): 345-53. 
[3] Dronkers J, Veldman A, Hoberg E, Van Der Waal C and Van Meeteren N. Prevention of pulmonary complications after upper abdominal surgery by preoperative intensive inspiratory muscle training a randomized controlled pilot study; 2008, (22): 134-142.

[4] Johnson R, Arozullah A, Neumayer L, Henderson W, Hosokawa $\mathrm{P}$ and Khuri S. Multivariable predictors of postoperative respiratory failure after general and vascular surgery: Results from the patient safety in surgery study. J Am Coll Surg; 2007, (204): 1188-98.

[5] Arozullah A, Daley J, Henderson W and Khuri S. Multifactorial risk index for predicting postoperative respiratory failure in men after major non cardiac surgery. The national veterans administration surgical quality improvement program. Ann Surg; 2000, (232): 242-53.

[6] Sharon M, Alice Y and Phil M. Postural drainage or flutter device in conjunction with breathing and coughing compared to breathing and coughing alone in improving secretion removal and lung function in bronchiectasis. Hong Kong Physical therapy Journal; 2003, 21: 29-36.

[7] Volsko T, Difiore J and Chatburn R. Performance comparison of two oscillating positive expiratory pressure devices: Acapella versus flutter. Respir Care; 2003, (48): 124-130.

[8] McIlwaine M. Physiotherapy and airway clearance techniques and devices. Paediatric Respiratory Reviews; 2006, (7): 220 222 .

[9] Perry A and Potter P. Mosby's Pocket Guide to nursing skills and procedures: Acapella device. USA: Elsevier Health Sciences. 2015, (8): 1-3.

[10] Wolkove N, Kamel H, Rotaple M and Baltzan M. Use of a mucus clearance device enhances the bronchodilator response in patients with stable COPD. Chest; 2002, (121): 702-707.

[11] Alves Silva C, Santos J, Jansen J and De Melo P. Laboratory evaluation of the Acapella device: Pressure characteristics under different conditions and a software tool to optimize its practical use. Respir Care.; 2009, 54 (11): 1480-1487.

[12] Mueller G, Bersch-Porada I, Koch-Borner S, Raab A, Jonker $\mathrm{M}$, Baumberger $\mathrm{M}$ and Michel $\mathrm{F}$. Laboratory evaluation of four different devices for secretion mobilization: Acapella choice, green and blue versus water bottle . Respiratory care; 2014, 59(5): 673-677.

[13] Nicolini A, CardiniF, Landucci N, Lanata S , Ferrari-Bravo M and Barlascini C. Effectiveness of treatment with high- frequency chest wall oscillation in patients with bronchiectasis. Pulmonary Medicine; 2013, 13 (21): 2-8.

[14] Mohamed A, Taha M and Bahey El-Deen H. Effects of positive expiratory pressure breathing on functional outcomes in patients with chronic obstructive pulmonary disease after major abdominal surgeries: randomized controlled trial. International Journal of Advanced Research; 2014, (2)7: 784801 .

[15] Johansson H, Sjöholm R, Stafberg A and Westerdah E. Breathing exercises with positive expiratory pressure after abdominal surgery-The current physical therapy practice in Sweden. J Anesthe Clinic Res; 2013, 6(4): 1-4.

[16] Abu-Rayan M, Afifi M, Othman M, El- Ganady A and Mikhael B. Evaluation of the single and combined roles of oscillating positive expiratory pressure device and conventional multimodality chest physiotherapy in mechanically ventilated COPD. Alexandria Journal of medicine; 2009, 45 (2): 354-364.

[17] Lamari N, Martins A, Oliveira J, Marino L and Valerio N Bronchiectasis and clearence physiotherapy: emphasis in postural drainage and percussion. Braz J Cardiovasc Surg; 2006, 21(2), 206-210.

[18] Augustine A, AlaparthiG, Anand R and Mahale A. Chest physiotherapy during immediate postoperative period among patients undergoing laparoscopic surgery- a randomized controlled pilot trail. International Journal of Biomedical And Advance Research; 2013, 4(2): 118-122.

[19] Abd Elgaphar S and Soliman G. The effect of early postanesthetic chest physiotherapy nursing intervention on patients undergoing upper abdominal surgery. Journal of Nursing and Health Science; 2015, 4 (4): 1940-2320.

[20] Pryor J, Tannenbaum E, Scott S, Burgess J, Cramer D, Gyi K and Hodson M. Beyond postural drainage and percussion: Airway clearance in people with cystic fibrosis. Journal of Cystic Fibrosis; 2010, 9 (3), 187-192.

[21] Patterson J, Bradley J, Hewitt O, Bradbury I, and Elborn J. Airway clearance in bronchiectasis: A randomized crossover trial of active cycle of breathing techniques versus Acapella. Respiration; 2005, 72: 239-242.

[22] Murray M, Pentland J and Hill A. A randomized crossover trial of chest physiotherapy in non-cystic fibrosis bronchiectasis. European Respiratory Journal; 2009, 34(5): 1086-1092. 